\title{
Cilengitide and Cetuximab Reduce Cytokine Production and Colony Formation of Head and Neck Squamous Cell Carcinoma Cells Ex Vivo
}

\author{
GUNNAR WICHMANN ${ }^{1 *}$, SUSAN CEDRA ${ }^{1 *}$, DAPHNE SCHLEGEL ${ }^{2}$, MARLEN KOLB $^{1}$, \\ SUSANNE WIEGAND ${ }^{1}$, ANDREAS BOEHM ${ }^{1}$, MATHIAS HOFER ${ }^{1}$ and ANDREAS DIETZ ${ }^{1}$ \\ ${ }^{1}$ Department of Otolaryngology, Head and Neck Surgery, University of Leipzig, Leipzig, Germany; \\ ${ }^{2}$ Department of Cranio-Maxillo-Facial Surgery, \\ Paracelsus Medical University Nuremberg Hospital South, Nuremberg, Germany
}

\begin{abstract}
Background/Aim: To analyze ex vivo effects of combined targeting of the epidermal growth factor-receptor (EGFR) by cetuximab (E) plus $\alpha V \beta 3$ and $\alpha V \beta 5$ integrins by cilengitide (Cil) on colony formation of epithelial cells $\left(C F_{e c}\right)$ and release of pro-angiogenetic and pro-inflammatory cytokines in head and neck squamous cell carcinoma (HNSCC) cells. Materials and Methods: Collagenase-IV digests of 43 histopathological confirmed HNSCC cases were seeded into laminin-coated 96-well plates containing E, Cil, or Cil $+E$ in final concentrations of $66.7 \mu \mathrm{g} / \mathrm{ml}, 10 \mu \mathrm{M}$, and $10 \mu M+66.7 \mu \mathrm{g} / \mathrm{ml}$, respectively. Following the FLAVINOassay protocol, supernatants were harvested after 3 days and adherent cells fixed in ethanol. Counting of $\mathrm{CF}_{e c}$ was facilitated by FITC-labeled pan-cytokeratin antibodies. Out of 43 HNSCC cases, 39 had adherent growth (mean $C F_{e c} \geq 4 /$ well in triplicate controls). Cytokines in supernatants were measured using ELISA were interleukin 6 (IL-6), monocyte chemoattractant protein $1(M C P-1)$ and vascular endothelial growth factor A (VEGFA). Results: $C F_{e c}$ on laminin was significantly reduced by Cil, E, and Cil+E. Cytokine measurements also revealed significant suppression of MCP-1, IL-6 and VEGFA. The strongest suppression of $C F_{e c}, M C P-1$ and VEGFA release was exerted by Cil and $E$
\end{abstract}

*These Authors contributed equally to this study.

Correspondence to: Gunnar Wichmann, Ph.D., Department of Otolaryngology, Head and Neck Surgery, University of Leipzig, Liebigstrasse 10-14, 04103 Leipzig, Germany. Tel: +49 3419721926, Fax: +49 3419721909, e-mail: gunnar.wichmann@medizin.unileipzig.de

Key Words: Head and neck cancer; head and neck squamous cell carcinoma, predictive assay, chemoresponse ex vivo, epidermal growth factor-receptor, cetuximab, cilengitide, integrin, targeted therapy. combined. Efficacy of Cil $+E$ exceeded those of the solely applied pharmaceutics but failed regarding significant synergism of both treatments as E was unable to significantly boost the effects of Cil. In contrast, IL-6 release was significantly suppressed by E but not by Cil, while their combination strongly reduced it. Conclusion: Combined targeting of EGFR and integrins with $E$ and Cil heightens their suppressive effects regarding $C F_{\text {ec }}$ as well as release of pro-angiogenetic and pro-inflammatory cytokines.

Tumors of the head and neck region, mostly head and neck squamous cell carcinomas (HNSCC), especially locally advanced and recurrent and/or metastatic HNSCC, are still related with poor outcome regarding 5-year survival time despite advancements in multimodal therapy strategies such as combined surgery with radio chemotherapy (1). Individual personalized therapy approaches need further investigation to overcome tumor heterogeneity and incalculable therapy response rates. Cytokines can potentially serve as biomarkers or even as new targets for therapy. This study focuses on monocyte chemoattractant protein (MCP-1), vascular endothelial growth factor A (VEGFA) and interleukin 6 (IL-6) which are potentially important in tumor proliferation, vascularization and metastasis (2). Recent results showed that MCP-1 is of special interest since inhibition of MCP-1 may improve the power of standard cytotoxic substances against HNSCC and on the other hand, MCP-1 may act as agent in tumor defense (3). In 2005 it was shown that IL-6 levels in cancer patients' serum correlates with tumor stage and lymph node status suggesting an active role of IL-6 in tumor progression (4). High IL-6 expression is also associated with poor prognosis and cisplatin resistance in HNSCC and other cancers (5). Since HNSCC are highly vascularized, it makes sense to investigate therapeutic options to interfere with tumor angiogenesis. Proangiogenic VEGFA is overexpressed in HNSCC and associates with elevated aggressiveness of the 
tumor (6-9). Targeted therapy such as inhibiting epidermal growth factor receptor (EGFR) with monoclonal antibody $\mathrm{E}$ is already used in clinical routine treatments $(10,11)$. As the first approved EGFR inhibitor for treatment of HNSCC in 2006, E improves survival in curative treatment of advanced HNSCC $(10,12)$ but also in first-line treatment of recurrent and/or metastatic HNSCC when teamed up with cisplatin and 5fluorouracil (5-FU) (13). Since EGFR upregulates VEGFA, a potential readout of the response of HNSCC to E may be VEGFA as reported in a number of studies (14-17). Other attractive targets are integrins as they are key players in tumor growth by binding to particular extracellular matrix (ECM) being crucial in cell communication, cell-to-cell and cell-toECM interaction, modulating signaling pathways important for cell growth, differentiation and survival (18). The RGD-peptide Cil is a selective inhibitor for $\alpha \mathrm{V} \beta 3$ and $\alpha \mathrm{V} \beta 5$ integrins (18, 19). As both integrins are excessively expressed during vascularization, and $\alpha \mathrm{V} \beta 5$ is overexpressed in various tumor entities including HNSCC, targeting these integrins by Cil is therefore promising (20). In phase I and II trial of Cil combined with $\mathrm{E}$, cisplatin and 5-FU, no dose-limiting toxicities were found $(13,21)$ which makes treatment with Cil combinations even more attractive for further investigations concerning heterogeneity in ex vivo response of HNSCC. This work demonstrates the effects of $\mathrm{Cil}$ and $\mathrm{E}$, alone and in combination on $\mathrm{CF}_{\mathrm{ec}}$ and release of MCP-1, IL-6 and VEGFA by HNSCC.

\section{Patients and Methods}

Patient characteristics. HNSCC samples of 43 patients were included in this study. With patients' informed consent, biopsies of tumor tissue were obtained during surgery or panendoscopy. 39 histopathologicallyconfirmed HNSCC patients of 34 males and 5 females (mean age at 60.3 years; Table I) could be analyzed regarding tumor cytokine production and colony formation after treating the specimens with or without Cil or $\mathrm{E}$ alone or in combination.

The primaries' localizations were mostly oropharynx $(24 / 39$; $61.5 \%)$, larynx and hypopharynx $(12 / 39 ; 30.8 \%)$; three HNSCC were localized in the nasopharynx $(1 / 39 ; 2.6 \%)$ and oral cavity $(2 / 39 ; 5.1 \%)$.

Only $8 / 39(21.5 \%)$ tumors were early stage (UICC I and II), while $31 / 39$ (79.5\%) cancers were locally advanced $(7 / 39,18.0 \%$, UICC III; 24/39, 61.5\%, UICC IV). 16/39 (41\%) had no lymph node metastasis, while $23 / 39(59.0 \%)$ had lymph node metastasis at first diagnosis (N1: 3/39, 7.7\%; N2a: $1 / 39,2.5 \%$; N2b: 6/39, $15.4 \%$; N2c: $12 / 39,30.8 \%$; N3: 1/39, 2.5\%); two patients had distant metastasis (M1: 2/39, 5.1\%). 8/39 (21.5\%) patients were nonsmokers, $4 / 39(10.3 \%)$ avoided alcohol. Only 2 patients had never consumed tobacco and alcohol; 1 patient denied information about these aspects (Table I).

FLAVINO-assay. The same procedures according the protocol of the FLAVINO assay were used as previously described (3). Briefly, freshly obtained tumor specimens were put into phenol red- and riboflavin-free medium supplemented with $10 \%$ fetal calf serum and antibiotics (TM). After mechanical disintegration and digestion by
$230 \mathrm{mU} / \mathrm{ml}$ collagenase IV (Sigma-Aldrich, Deisenhofen, Germany) 10,000 viable HNSCC cells were added to wells in triplicates coated with human laminin (Roche, Germany) containing either $66.7 \mu \mathrm{g} / \mathrm{ml}$ $\mathrm{E}, 10 \mu \mathrm{M}$ Cil, Cil+E, or (for reference) medium alone, adjusting the total volume to $300 \mu \mathrm{L}$. According to the FLAVINO-assay protocol, supernatants were harvested after 3 days and adherent cells were ethanol-fixated. Counting of colonies of epithelial cells was facilitated by FITC-labeled pan-cytokeratin antibodies. 39 HNSCC had adherent growth (mean $\mathrm{CF}_{\mathrm{ec}} \geq 4 /$ well in triplicate controls).

ELISA assay. The influence of Cil and E on the cytokine secretion by HNSCC was analyzed using ELISA. The levels of cytokines IL6, MCP-1 and VEGFA in supernatants were measured using indirect sandwich ELISAs (OptEIA Kits; BD Biosciences, Heidelberg, Germany) following the manufacturers' instructions and using tetramethyl benzidine as substrate. The optical density of each well was determined measuring the optical density at $\lambda_{1}=450 \mathrm{~nm}$ and $\lambda_{2}=620$ $\mathrm{nm}$ on the Synergy $2^{\mathrm{TM}}$ multi-mode microplate reader (BioTek Instruments, Inc., Winooski, VT, USA); calibration curves were calculated using the Gen5 software (BioTek). The lower limit of detection for all cytokines was $\leq 4 \mathrm{pg} / \mathrm{ml}$.

Statistical analysis. All data shown herein are based on triplicate measurements. Differences were compared by Student's $t$-test for paired samples using SPSS Statistics for Windows, version 20.0.0 (SPSS Inc., Chicago, IL, USA); $p$-values $\leq 0.05$ were regarded as significant.

\section{Results}

Colony formation by HNSCC and release of IL-6, MCP-1 and VEGFA demonstrated a huge amount of heterogeneity. In untreated controls no significant association were found with localization of the primary tumor, $\mathrm{T}$ category, $\mathrm{N}$ category, UICC stage, risk factors (pack years of tobacco smoking, daily alcohol consumption), sex and other patient characteristics regarding un-normalized readouts.

Treatments however, showed different effects on all analyzed parameters when using $t$-tests for paired samples compared to heteroscedastic $t$-tests for comparisons of measures normalized to individual controls. The effects of $\mathrm{E}$, Cil, and Cil+E are shown in Figure 1 for $\mathrm{CF}_{\mathrm{ec}}$, IL-6, MCP-1, and VEGFA normalized to controls. Targeting EGFR and integrins is suppressing $\mathrm{CF}_{\mathrm{ec}}$ and cytokine release but shows variable strength of effects on individual readouts and among HNSCC patients. This is demonstrated by the scatter plots of Table II showing the correlation of normalized data for $\mathrm{CF}_{\mathrm{ec}}$, IL-6, MCP-1 and VEGFA regarding the three treatments.

Cilengitide and cetuximab affect colony formation and cytokine production. In contrast to an earlier study with smaller sample size and slightly different experimental conditions regarding coating of cell-culture microtiter-plates (3), Cil suppressed significantly $\mathrm{CF}_{\mathrm{ec}}$ on laminin ( $p=0.0003$; Table II). However, also E $(p=0.004)$ and Cil and $\mathrm{E}$ combined $(p=0.0003)$ reduced $\mathrm{CF}_{\mathrm{ec}}$ (Table II). IL-6 production was not significantly affected by Cil $(p=0.07)$ and only slightly by $\mathrm{E}(p=0.03)$ alone but combining Cil and 
Table I. Characteristics of HNSCC patients and treatment for 39 patients with cytokine measurements among the cohort of 43 patients with sufficient colony formation $\left(\mathrm{CF}_{e c} \geq 4\right.$ per well of untreated control in laminin-coated microtiter-plates) allowing for reliable response assessment.

\begin{tabular}{|c|c|c|c|c|c|c|c|c|c|c|c|c|c|c|c|c|}
\hline $\begin{array}{l}\text { Patient } \\
\text { ID }\end{array}$ & Gender & $\begin{array}{c}\text { Localization } \\
\text { of primary }\end{array}$ & $\begin{array}{c}\text { Age at } \\
\text { diagnosis } \\
\text { (years) }\end{array}$ & $\begin{array}{l}\text { UICC } \\
\text { stage }\end{array}$ & $\mathrm{T}$ & $\mathrm{N}$ & M & Therapy & $\begin{array}{c}\text { Therapy } \\
\text { monomodal } v s . \\
\text { multimodal }\end{array}$ & $\begin{array}{c}\text { Tobacco } \\
\text { smoking } \\
\text { (Pack Years) }\end{array}$ & Alcohol & Grading & Pn & $\mathrm{V}$ & $\mathrm{L}$ & $\mathrm{R}$ \\
\hline 1 & M & oroph & 57.9 & III & 2 & 1 & 0 & Op+PORT & multi & 45 & $\geq 60$ & 3 & 0 & 0 & 1 & 0 \\
\hline 2 & M & larynx & 59.5 & III & 3 & 0 & 0 & Op+PORT & multi & 0 & 0 & 2 & 0 & 0 & 0 & 0 \\
\hline 3 & M & hypo & 57.9 & IVA & 3 & $2 \mathrm{c}$ & 0 & $\mathrm{ICh}+\mathrm{Op}+\mathrm{RT}$ & multi & 40 & $<30$ & 2 & 1 & 0 & 1 & 0 \\
\hline 5 & $\mathrm{~F}$ & oroph & 78.3 & II & 2 & 0 & 0 & Op & mono & 50 & $\geq 60$ & 3 & 0 & 0 & 1 & 0 \\
\hline 6 & M & oroph & 58.2 & IVA & $4 a$ & $2 c$ & 0 & pRChT & multi & 40 & $<60$ & 3 & -- & -- & -- & -- \\
\hline 7 & M & larynx & 69.7 & III & 3 & 0 & 0 & Op & mono & -- & -- & 2 & 0 & 0 & 0 & 0 \\
\hline 8 & M & oroph & 48.9 & II & 2 & 0 & 0 & Op+PORT & multi & 40 & $<30$ & 2 & 1 & 0 & 0 & 0 \\
\hline 9 & M & hypo & 43.8 & IVA & 1 & $2 \mathrm{a}$ & 0 & $\mathrm{Op}+\mathrm{PORT}$ & multi & 30 & $\geq 60$ & 2 & 0 & 0 & 0 & 0 \\
\hline 10 & M & oroph & 63.2 & IVA & 1 & $2 b$ & 0 & $\mathrm{ICh}+\mathrm{Op}+\mathrm{RT}$ & multi & 0 & $<60$ & 3 & 0 & 0 & 1 & 0 \\
\hline 11 & $\mathrm{~F}$ & larynx & 64.1 & IVA & $4 \mathrm{a}$ & $2 \mathrm{c}$ & 0 & $\mathrm{Op}$ & mono & 8 & $<30$ & 2 & 0 & 0 & 1 & 1 \\
\hline 12 & M & hypo & 73.2 & IVA & $4 \mathrm{a}$ & 1 & 0 & Op & mono & 20 & $<30$ & 2 & -- & -- & -- & -- \\
\hline 13 & M & oroph & 66.3 & II & 2 & 0 & 0 & Op & mono & 40 & $<30$ & 2 & 0 & 0 & 0 & 0 \\
\hline 14 & M & oroph & 49.7 & III & 3 & 0 & 0 & $\mathrm{ICh}+\mathrm{Op}+\mathrm{RT}$ & multi & 45 & $\geq 60$ & 2 & 1 & 0 & 1 & -- \\
\hline 15 & M & hypo & 56.6 & IVC & $4 \mathrm{a}$ & $2 \mathrm{c}$ & 1 & pRChT & multi & -- & $<30$ & 2 & -- & -- & -- & -- \\
\hline 16 & $\mathrm{~F}$ & nasoph & 50.8 & IVA & $4 a$ & 0 & 0 & Op+PORChT & multi & 0 & $<30$ & 3 & 0 & 1 & 0 & 0 \\
\hline 17 & M & oral & 77.3 & II & 2 & 0 & 0 & Op+PORT & multi & 80 & $<60$ & 3 & 1 & 0 & 0 & 0 \\
\hline 19 & M & oroph & 53.7 & IVB & 3 & 3 & 0 & Op+PORT & multi & 30 & $\geq 60$ & 2 & 1 & 0 & 1 & 0 \\
\hline 20 & M & larynx & 66.3 & I & 1 & 0 & 0 & Op & mono & 30 & $\geq 60$ & 2 & 0 & 0 & 1 & 0 \\
\hline 21 & M & oroph & 49.0 & III & 3 & 0 & 0 & Op & mono & 30 & $<30$ & 3 & 0 & 0 & 1 & 0 \\
\hline 22 & M & hypo & 49.3 & IVC & $4 \mathrm{a}$ & $2 c$ & 1 & pRChT & multi & 45 & $\geq 60$ & 3 & -- & -- & -- & -- \\
\hline 24 & M & oroph & 59.2 & III & 3 & 1 & 0 & Op & mono & 0 & $<30$ & 2 & 0 & 0 & 1 & 0 \\
\hline 25 & M & oroph & 56.8 & IVA & $4 \mathrm{a}$ & $2 b$ & 0 & Op+PORChT & multi & 40 & $<60$ & 3 & 1 & 1 & 1 & 0 \\
\hline 26 & $\mathrm{~F}$ & oroph & 74.2 & I & 1 & 0 & 0 & Op & mono & 0 & 0 & 2 & 1 & 0 & 0 & 0 \\
\hline 27 & M & oroph & 61.1 & IVA & 1 & $2 c$ & 0 & Op+PORChT & multi & 90 & $<60$ & 3 & 0 & 0 & 1 & 0 \\
\hline 28 & $\mathrm{~F}$ & larynx & 50.4 & IVA & 3 & $2 \mathrm{c}$ & 0 & Op+PORChT & multi & 40 & -- & 2 & 0 & 1 & 1 & 0 \\
\hline 29 & M & oroph & 58.7 & IVA & 3 & $2 c$ & 0 & Op+PORT & multi & 60 & $\geq 60$ & 2 & -- & -- & -- & -- \\
\hline 30 & M & oroph & 74.0 & IVA & 3 & $2 b$ & 0 & Op+PORChT & multi & 0 & $<30$ & 2 & 1 & 1 & 1 & 0 \\
\hline 32 & M & oroph & 56.0 & IVA & $4 \mathrm{a}$ & $2 \mathrm{c}$ & 0 & Op & mono & 40 & $<30$ & 2 & 1 & 1 & 1 & 0 \\
\hline 33 & M & oroph & 60.0 & IVA & 3 & $2 b$ & 0 & Op & mono & 0 & $<30$ & 3 & 1 & 0 & 1 & 0 \\
\hline 34 & M & oroph & 64.4 & IVA & $4 \mathrm{a}$ & 0 & 0 & Op+PORT & multi & 0 & $<30$ & 3 & 1 & 0 & 0 & 0 \\
\hline 35 & M & larynx & 57.2 & IVA & $4 \mathrm{a}$ & $2 c$ & 0 & $\mathrm{ICh}+\mathrm{Op}+\mathrm{RT}$ & multi & 80 & $\geq 60$ & 3 & 0 & 0 & 1 & 0 \\
\hline 36 & M & oroph & 70.3 & IVA & $4 \mathrm{a}$ & $2 c$ & 0 & Op+PORT & multi & 50 & 0 & 2 & 0 & 0 & 1 & 0 \\
\hline 37 & M & oroph & 51.1 & IVA & 3 & $2 b$ & 0 & $\mathrm{ICh}+\mathrm{Op}+\mathrm{RT}$ & multi & 30 & $<30$ & 3 & 0 & 0 & 0 & 0 \\
\hline 38 & M & oroph & 41.7 & IVA & $4 \mathrm{a}$ & $2 \mathrm{c}$ & 0 & Op & mono & 20 & $<60$ & 3 & 0 & 1 & 1 & 0 \\
\hline 39 & M & oral & 55.9 & II & 2 & 0 & 0 & Op+PORT & multi & 30 & $\geq 60$ & 3 & 1 & 0 & 1 & 0 \\
\hline 40 & M & hypo & 71.7 & II & 2 & 0 & 0 & Op & mono & 45 & $<60$ & 2 & 0 & 0 & 0 & 0 \\
\hline 41 & M & oroph & 83.1 & III & 3 & 0 & 0 & Op & mono & 60 & 0 & -- & -- & -- & -- & 1 \\
\hline 42 & M & oroph & 65.5 & IVA & $4 \mathrm{a}$ & 0 & 0 & Op & mono & 125 & $<60$ & 2 & 1 & 0 & 1 & 0 \\
\hline 43 & M & oroph & 48.2 & IVA & 3 & $2 b$ & 0 & $\mathrm{ICh}+\mathrm{Op}+\mathrm{RT}$ & multi & 35 & $\geq 60$ & 2 & 0 & 1 & 1 & 0 \\
\hline
\end{tabular}

F, Female; M, male; oroph, oropharynx; hypo, hypopharynx; oral, oral cavity; nasoph, nasopharynx; Op, surgery; RT, radiotherapy; ICh, inductionchemotherapy; PORT, post-operative radiotherapy; PORChT, post-operative radiochemotherapy; pRChT, primary concomitant radiochemotherapy.

E led to considerable suppression of IL-6 ( $p=0.00024)$. All treatments altered MCP-1 production significantly. Cil showed the strongest impact on $\mathrm{MCP}-1$ production $(p=0.00008)$ followed by Cil+E $(p=0.00038)$ and $\mathrm{E}$ alone $(p=0.01)$. While $\mathrm{E}$ alone was not able to achieve significant effects on VEGFA $(p=0.14)$, Cil $(p=0.037)$ or Cil $+\mathrm{E}$ $(p=0.03)$ substantially suppressed VEGFA release.

As shown in Table II, this study proves that for chemoresponse assessment measuring cytokine production is superior to colony formation. Readouts of $\mathrm{CF}_{\mathrm{ec}}$ were more inconsistent than cytokine release in triplicate measurements although effects of Cil and $\mathrm{E}$ were considerable.

\section{Discussion}

By analyzing 39 HNSCC ex vivo we were able to demonstrate a significant impact of EGFR and integrin inhibition on $\mathrm{CF}_{\mathrm{ec}}$ and production of IL-6, MCP-1 and 
VEGFA in the majority of HNSCC samples (Figure 1, Table II). However, the inter-individual heterogeneity calls for a more detailed analysis. As far as we are aware, there are no other studies regarding this specific topic. Our findings showed that $10 \mu \mathrm{M}$ Cil in HNSCC tumor cells ex vivo, may suppress production of MCP-1 and VEGFA as well as $\mathrm{CF}_{\mathrm{ec}}$ significantly. We demonstrated that activity of Cil increased in binary combination with E. Reynolds et al. demonstrated in 2009 that low dose integrin inhibition can lead to altered expression of $\alpha \mathrm{V} \beta 3$ and VEGFR-2 resulting in tumor angiogenesis and proliferation (22). In our study, some individual tumor samples reacted paradoxically with an increase in VEGFA production and $\mathrm{CF}_{\mathrm{ec}}$ suggesting dose dependency of Cil effects.

In the ADVANTAGE study, Cil was given as fourth component in addition to cisplatin, 5-FU and $\mathrm{E}$ to patients with recurrent and/or metastatic HNSCC (13). In this setting no benefit in overall survival could be demonstrated for Cil. This may be related to limited response in this heavily pretreated population that might be exploited already by the three other drugs to its maximum extend. This is also strengthened by the CeFCiD study that was unable to demonstrate superiority of the fourth component in HNSCC using the otherwise highly active taxol docetaxel $(23,24)$. Therefore, ADVANTAGE which is the only clinical trial of Cil in HNSCC (13) appears to be inadequate to elucidate the full potential of Cil in HNSCC and may not stand against potential efficacy of Cil or Cil+E.

To our knowledge, there are so far no clinical trials in HNSCC analyzing solely Cil or Cil in binary combination together with one additional drug, e.g. E. As most newly emerging drugs are tested, the sole investigation of Cil combined with cisplatin, 5-FU and E may have limited the chance to demonstrate any benefit of the fourth component Cil. No dose limiting toxicities and only mild side effects of Cil were observed (13) and potential benefit from Cil is highlighted by our data. This argues for new clinical trials as there might still be potential for including this pentapeptide in targeted therapy of eligible patients. These patients, as suggested by our data (Figure 1, Table II), could eventually be identified by ex vivo testing.

EGFR targeting by E improves overall survival in HNSCC patients $(10,11)$. E treatment decreased considerably the release of IL-6, MCP-1, VEGFA and $\mathrm{CF}_{\mathrm{ec}}$ in our ex vivo experiments. As IL-6, MCP-1 and VEGFA could serve as prognostic biomarkers and increased levels of IL-6 (4), MCP$1(3,25)$ and VEGFA $(6-8,26,27)$ are associated with inflammation and poor outcome, we interpret their reduction towards normal levels as indicators for response. The high degree of correlation of reduced colony formation and reduced cytokine release of our samples supports this interpretation. Pathways of EGFR and VEGFA are closely linked since they share common downstream pathways effecting tumor cells

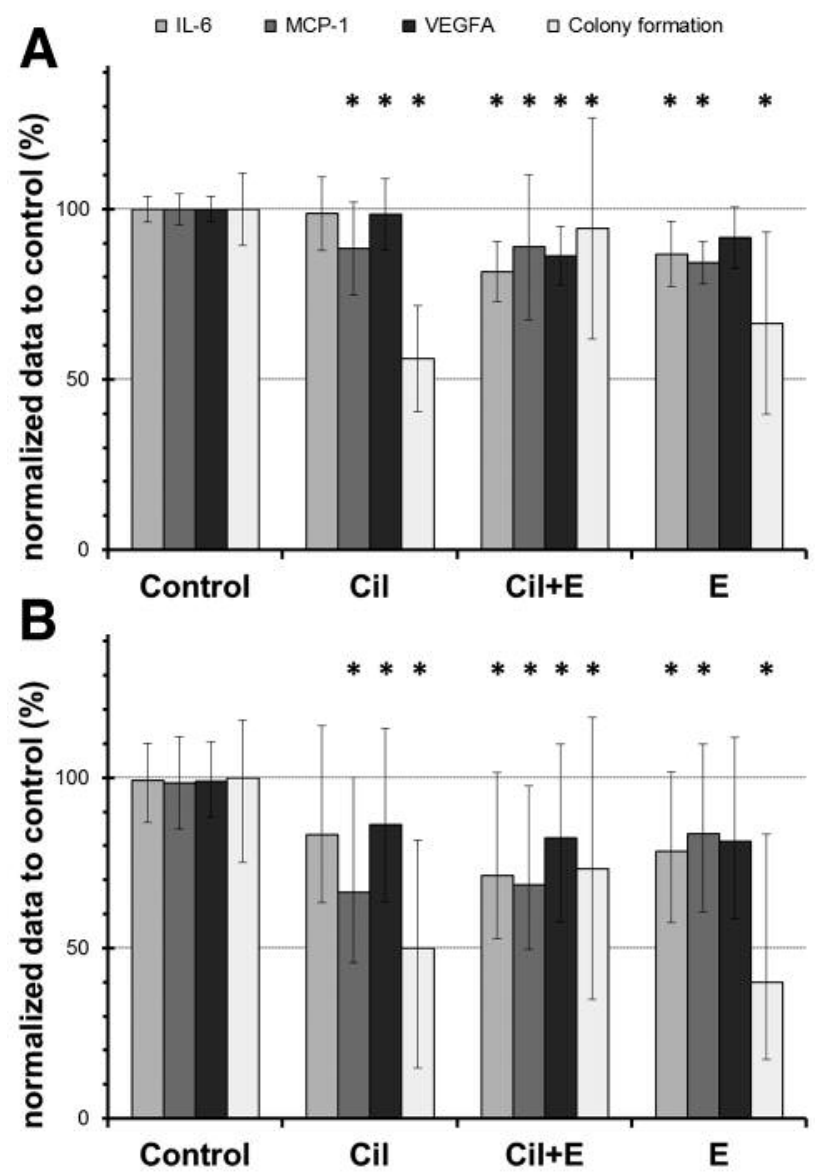

Figure 1. Effect of cilengitide (Cil), cetuximab (E) and Cil+E on production of IL-6, MCP-1, VEGFA and colony formation of epithelial cells $\left(C F_{e c}\right)$ normalized to individual control. (A) Mean and 95\% confidence interval; (B) median and interquartile range of $39 \mathrm{HNSCC}$. Asterisks indicate significance ( $p$-value $\leq 0.05$ ).

directly and indirectly (28). Overexpression of EGFR leads to increased VEGFA expression $(14,29)$. This study, showing that VEGFA release was reduced after EGFR targeting, highlights VEGFA as a suitable biomarker for response to $\mathrm{E}$ $(14,29,30)$. Our measurements highlight the suppressing effect of EGFR blockage on VEGFA and IL-6 as well as on MCP-1 (Figure 1, Table II) solidifying the value of $E$ in anticancer therapy regimes.

In this study, actual tumor samples - primary HNSCC without prolonged propagation by cultivation under artificial conditions leading to loss of normal features and chemoresponse - were exposed to anticancer agents ex vivo. We did not use cell lines in order to provide most biologically appropriate conditions bypassing common problems with cell lines as they are highly selected and sometimes artificially immortalized hindering transfer of such data to treatment of individual tumors. We saw real- 

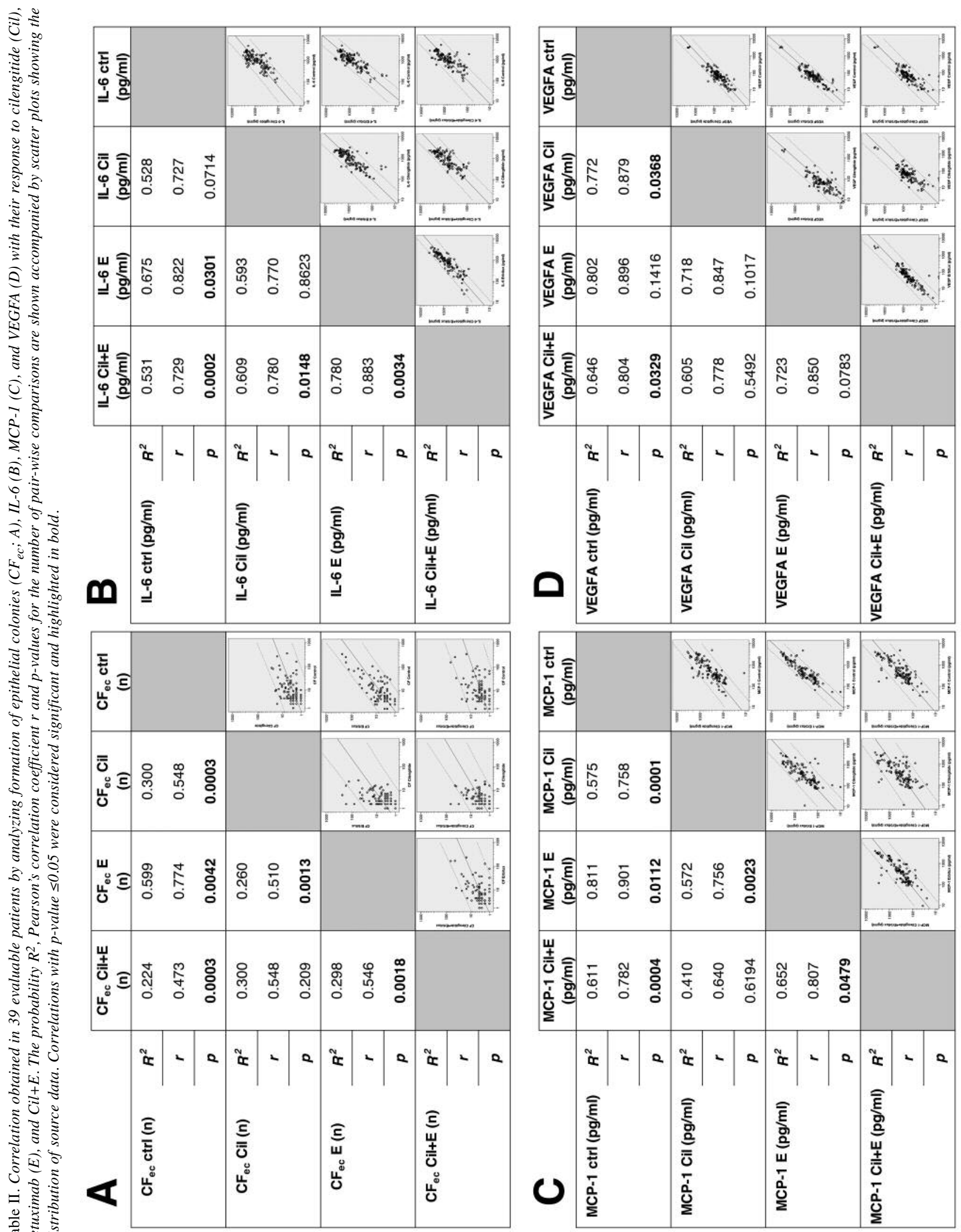
world heterogeneity in response to treatment as individual tumors responded differently to the same treatment. The impact of Cil and $\mathrm{E}$ varied enormously depending on distinct tumor features. This aspect suggests the presence of subgroups within HNSCC patients of which some react with suppressed cytokine production to treatment and some which react with a boost of cytokine release.

Targeting $\alpha \mathrm{V} \beta 3$ and $\alpha \mathrm{V} \beta 5$ integrins by Cil and EGFR by E leads to reduced $\mathrm{CF}_{\mathrm{ec}}$ and cytokine release proving that Cil does have a potential in cancer treatment. Analyzing cytokine release is superior to counting epithelial cell colonies concerning chemoresponse testing in order to select suitable patients which could benefit from targeted therapy.

\section{Acknowledgements}

The Authors would like to thank all patients and their families for participation in this study.

\section{References}

1 Pulte D and Brenner H: Changes in survival in head and neck cancers in the late 20th and early 21st century: a period analysis. Oncologist 15(9): 994-1001, 2010.

2 Pries R and Wollenberg B: Cytokines in head and neck cancer. Cytokine Growth Factor Rev 17(3): 141-146, 2006.

3 Wichmann G, Körner C, Boehm A, Mozet C and Dietz A: Stimulation by monocyte chemoattractant protein-1 modulates the ex vivo colony formation by head and neck squamous cell carcinoma cells. Anticancer Res 35(7): 3917-3924, 2015.

4 Riedel F, Zaiss I, Herzog D, Götte K, Naim R and Hörmann K: Serum levels of interleukin-6 in patients with primary head and neck squamous cell carcinoma. Anticancer Res 25(4): 2761$2765,2005$.

5 Gao J, Zhao S and Halstensen TS: Increased interleukin-6 expression is associated with poor prognosis and acquired cisplatin resistance in head and neck squamous cell carcinoma. Oncol Rep 35(6): 3265-3274, 2016.

6 Kyzas PA, Cunha IW and Ioannidis JP: Prognostic significance of vascular endothelial growth factor immunohistochemical expression in head and neck squamous cell carcinoma: a metaanalysis. Clin Cancer Res 11(4): 1434-1440, 2005.

7 Riedel F, Götte K, Schwalb J, Wirtz H, Bergler W and Hörmann $\mathrm{K}$ : Serum levels of vascular endothelial growth factor in patients with head and neck cancer. Eur Arch Otorhinolaryngol 257(6): 332-336, 2000.

8 Vassilakopoulou M, Psyrri A and Argiris A: Targeting angiogenesis in head and neck cancer. Oral Oncol 51(5): 409415, 2015.

9 Kim KJ, Li B, Winer J, Armanini M, Gillett N, Phillips HS and Ferrara N: Inhibition of vascular endothelial growth factorinduced angiogenesis suppresses tumour growth in vivo. Nature 362(6423): 841-844, 1993.

10 Bonner JA, Harari PM, Giralt J, Azarnia N, Shin DM, Cohen RB, Jones CU, Sur R, Raben D, Jassem J, Ove R, Kies MS, Baselga J, Youssoufian H, Amellal N, Rowinsky EK and Ang KK: Radiotherapy plus cetuximab for squamous-cell carcinoma of the head and neck. N Engl J Med 354(6): 567-578, 2006.
11 Vermorken JB, Mesia R, Rivera F, Remenar E, Kawecki A, Rottey S, Erfan J, Zabolotnyy D, Kienzer HR, Cupissol D, Peyrade F, Benasso M, Vynnychenko I, De Raucourt D, Bokemeyer C, Schueler A, Amellal N and Hitt R: Platinumbased chemotherapy plus cetuximab in head and neck cancer. $\mathrm{N}$ Engl J Med 359(11): 1116-1127, 2008.

12 Dietz A, Boehm A, Mozet C, Wichmann G and Giannis A: Current aspects of targeted therapy in head and neck tumors. Eur Arch Otorhinolaryngol 265(Suppl 1): 3-12, 2008.

13 Vermorken JB, Peyrade F, Krauss J, Mesía R, Remenar E, Gauler TC, Keilholz U, Delord JP, Schafhausen P, Erfán J, Brümmendorf TH, Iglesias L, Bethe U, Hicking C and Clement PM: Cisplatin, 5-fluorouracil, and cetuximab (PFE) with or without cilengitide in recurrent/metastatic squamous cell carcinoma of the head and neck: results of the randomized phase I/II ADVANTAGE trial (phase II part). Ann Oncol 25(3): 682-688, 2008.

14 O-charoenrat P, Rhys-Evans P, Modjtahedi H and Eccles SA: Vascular endothelial growth factor family members are differentially regulated by c-erbB signaling in head and neck squamous carcinoma cells. Clin Exp Metastasis 18(2): 155-161, 2000.

15 Jouan-Hureaux V, Boura C, Merlin JL and Faivre B: Modulation of endothelial cell network formation in vitro by molecular signaling of head and neck squamous cell carcinoma (HNSCC) exposed to cetuximab. Microvasc Res 83(2): 131137, 2011.

16 Moehler M, Frings C, Mueller A, Gockel I, Schimanski CC, Biesterfeld S, Galle PR and Holtmann MH: VEGF-D expression correlates with colorectal cancer aggressiveness and is downregulated by cetuximab. World J Gastroenterol 14(26): 4156-4167, 2008.

17 Vincenzi B, Santini D, Russo A, Gavasci M, Battistoni F, Dicuonzo G, Rocci L, Rosaria VM, Gebbia N and Tonini G: Circulating VEGF reduction, response and outcome in advanced colorectal cancer patients treated with cetuximab plus irinotecan. Pharmacogenomics 8(4): 319-327, 2007.

18 Goodman SL, Hölzemann G, Sulyok GA and Kessler H: Nanomolar small molecule inhibitors for alphav(beta)6, alphav(beta)5, and alphav(beta)3 integrins. J Med Chem 45(5): 1045-1051, 2002.

19 Mas-Moruno C, Rechenmacher F and Kessler H: Cilengitide: The first anti-angiogenic small molecule drug candidate.design, synthesis and clinical evaluation. anti-cancer agents in medicinal chemistry 10: 753-768, 2010.

20 Rüegg C, Dormond O and Mariotti A: Endothelial cell integrins and COX-2: mediators and therapeutic targets of tumor angiogenesis. Biochim Biophys Acta 1654(1): 51-67, 2004.

21 Vermorken JB, Guigay J, Mesia R, Trigo JM, Keilholz U, Kerber A, Bethe U, Picard M and Brummendorf TH: Phase I/II trial of cilengitide with cetuximab, cisplatin and 5-fluorouracil in recurrent and/or metastatic squamous cell cancer of the head and neck: findings of the phase I part. Br J Cancer 104(11): 1691-1696, 2011.

22 Reynolds AR, Hart IR, Watson AR, Welti JC, Silva RG, Robinson SD, Da Violante G, Gourlaouen M, Salih M, Jones MC, Jones DT, Saunders G, Kostourou V, Perron-Sierra F, Norman JC, Tucker GC, Hodivala-Dilke KM: Stimulation of tumor growth and angiogenesis by low concentrations of RGD-mimetic integrin inhibitors. Nat Med 15(4): 392-400, 2009. 
23 Knoedler M, Gauler T, Dietz A, Grünwald V, StoehlmacherWilliams J, Knipping S, Schroeder M, Guntinas-Lichius O, Frickhofen N, Lindemann H, Fietkau R, Haxel B, Junghanß C, Maschmeyer G, Zipfel M, Martus P and Keilholz U: Cetuximab (c), fluorouracil (F) and cisplatin (P) alone or with docetaxel (D) for recurrent/metastatic (RM) head and neck cancer (HNSCC). Final analysis of AIO trial \# 1108 - CeFCiD. Ann Oncol 25(suppl 4): iv340 doi:10.1093/annonc/mdu340.2, 2014.

24 Knoedler M, Gauler TC, Gruenwald V, Matzdorff A, Schroeder M, Dietz A, Jordan WO, Arnold D, Hennemann B, Hofele C, Weissinger F, Eberhardt W and Keilholz U: Phase II study of cetuximab in combination with docetaxel in patients with recurrent and/or metastatic squamous cell carcinoma of the head and neck after platinum-containing therapy: a multicenter study of the Arbeitsgemeinschaft Internistische Onkologie. Oncology 84(5): 284-289, 2013.

25 Wang H, Zhang Q, Kong H, Zeng Y, Hao M, Yu T, Peng J, Xu $\mathrm{Z}$, Chen J and Shi H: Monocyte chemotactic protein-1 expression as a prognosic biomarker in patients with solid tumor: a meta analysis. Int J Clin Exp Pathol 7(7): 3876-3886, 2014.

26 Chung TK, Warram J, Day KE, Hartman Y and Rosenthal EL: Time-dependent pretreatment with bevacuzimab increases tumor specific uptake of cetuximab in preclinical oral cavity cancer studies. Cancer Biol Ther 16(5): 790-798, 2015.
27 Carmeliet P: VEGF as a key mediator of angiogenesis in cancer. Oncology 69(Suppl 3): 4-10, 2005.

28 Herbst RS, Johnson DH and Mininberg E: Phase I/II trial evaluating the antivascular endothelial growth factor monoclonal antibody bevacizumab in combination with the HER-1/epidermal growth factor receptor tyrosine kinase inhibitor erlotinib for patients with recurrent non-small-cell lung cancer. J Clin Oncol 23: 2544-2555, 2005.

29 Larsen AK, Ouaret D, El Ouadrani K and Petitprez A: Targeting EGFR and $\operatorname{VEGF}(\mathrm{R})$ pathway cross-talk in tumor survival and angiogenesis. Pharmacol Ther 131(1): 80-90, 2011.

30 Tabernero J: The role of VEGF and EGFR inhibition: implications for combining anti-VEGF and anti-EGFR agents. Mol Cancer Res 5(3): 203-220, 2007.

Received November 23, 2016

Revised December 22, 2016

Accepted December 28, 2016 